\title{
Trafficking of Lysosomal Enzymes in Normal and Disease States
}

\author{
Stuart Kornfeld \\ Departments of Internal Medicine and Biological Chemistry, Division of Hematology-Oncology, \\ Washington University School of Medicine, St. Louis, Missouri 63110
}

The lysosomal storage disorders constitute greater than 30 separate entities, the majority of which result from the absence of one or more lysosomal enzymes. While many of these disorders are due to the failure to synthesize an active form of the relevant enzyme, an increasing number of cases are being reported where the defect lies in the inability to transport an active enzyme to the lysosome. Recent work from many laboratories has greatly enhanced our understanding of how newly synthesized lysosomal enzymes are segregated from secretory proteins and packaged into lysosomes. Studies of patients with defects in this sorting pathway have facilitated the unraveling of this complex process while also serving to pinpoint the exact site where the targeting has gone awry. The purpose of this review is to summarize our current understanding of lysosomal enzyme targeting and to discuss the defects in this pathway that have been documented thus far.

Lysosomal enzymes, along with secretory proteins and plasma membrane proteins, are synthesized on membranebound polysomes in the rough endoplasmic reticulum (Fig. 1). Each of these proteins contains a hydrophobic amino terminal signal peptide which interacts with a signal recognition particle, an 11S ribonucleoprotein, and thereby initiates the vectoral transport of the nascent protein across the endoplasmic reticulum membrane into the lumen of that organelle (1-3). Since lysosomal enzymes and secretory proteins share this mechanism for membrane translocation, they are mixed together in the lumen of the endoplasmic reticulum. The lysosomal enzymes (as well as most of the secretory and plasma membrane proteins) undergo cotranslational glycosylation of selected Asn residues. This glycosylation step involves the en bloc transfer of a large preformed oligosaccharide (three glucose, nine mannose, and two $\mathrm{N}$-acetylglucosamine residues) from a lipid-linked intermediate to the nascent polypeptide (4). In the endoplasmic reticulum, the signal peptide is cleaved, and the processing of the Asn-linked oligosaccharide begins by the excision of three glucoses and one of the mannose residues from the oligosaccharide.

The proteins then move, by vesicular transport, to the Golgi stack where they undergo a variety of posttranslational modifications and are sorted for targeting to the proper destination, e.g., lysosome, secretory granule, or plasma membrane. During passage through the Golgi, the oligosaccharides on secretory and membrane glycoproteins are processed to sialic acid-containing complex-type units. While some of the oligosaccharides on lysosomal enzymes undergo similar processing, most undergo a

Received for publication 11 September 1985.

J. Clin. Invest.

(C) The American Society for Clinical Investigation, Inc.

0021-9738/86/01/0001/06 \$1.00

Volume 77, January 1986, 1-6 different series of modifications. The critical modification is the acquisition of phosphomannosyl residues; these serve as the essential component of a recognition marker which leads to binding to high affinity receptors (mannose-6-phosphate[M-6-P $]^{1}$ receptors) and subsequent translocation to lysosomes (5). This recognition marker is generated by the sequential action of two Golgi enzymes. First, $N$-acetylglucosaminylphosphotransferase (phosphotransferase) transfers $N$-acetylglucosamine-1-phosphate from the nucleotide sugar uridine diphosphate $-N$-acetylglucosamine to selected mannose residues on lysosomal enzymes to give rise to a phosphodiester intermediate $(6,7)$. Then, $N$-acetylglucosamine-1-phosphodiester $\alpha-N$-acetylglucosaminidase removes the $N$-acetylglucosamine residue to expose the recognition signal $(8,9)$. Partially purified phosphotransferase phosphorylates lysosomal enzymes at least 100 -fold better than nonlysosomal glycoproteins which contain identical high mannosetype oligosaccharides $(7,10,11)$. Isolated high mannose oligosaccharides and glycopeptides are extremely poor substrates for the enzyme, indicating that the high affinity interaction between the transferase and lysosomal enzymes is mediated primarily by protein-protein interactions. This has been shown directly by demonstrating that deglycosylated lysosomal enzymes are potent inhibitors of the phosphorylation of intact lysosomal enzymes (11). Based on these data, it has been proposed that the phosphotransferase recognizes a protein domain that is common to all lysosomal enzymes, but is absent in nonlysosomal glycoproteins $(10,11)$; however, the identity of this common protein domain is unknown. Since heat-denaturated lysosomal enzymes or proteolytic fragments of lysosomal enzymes do not serve as substrates for the phosphorylating enzyme, it appears that the conformation of the protein is important for the expression of the recognition marker. This can be explained in several ways. First, the recognition marker may be a simple primary sequence that is only recognized when it is in the proper conformation. Alternatively, several simple sequences or even individual amino acid residues from different regions of the linear sequence could be recognized, but only when the protein is properly folded and they are brought into the correct orientation. If one assumes that the Michaelis constant $\left(K_{\mathrm{m}}\right)$ is primarily a measure of the affinity of phosphotransferase for the lysosomal enzyme recognition site, then the "specific" recognition affinity is near $10^{-3}$ to $10^{-4} \mathrm{M}$ (difference in apparent $K_{\mathrm{m}}$ between nonlysosomal glycoproteins and lysosomal enzymes). This value is compatible with a relatively small recognition region of about two to three amino acids (12). Another possibility, which seems the least likely, is that there is a unique higher order conformation that is shared by all lysosomal enzymes and is independent of a com-

1. Abbreviations used in this paper: M-6-P, mannose-6-phosphate; $\mathrm{M}$ 6-P receptor ${ }^{\mathrm{CD}}$, cation-dependent $\mathrm{M}-6-\mathrm{P}$ receptor; $\mathrm{M}-6-\mathrm{P}^{\mathrm{CI}}$, cation-independent M-6-P receptor. 


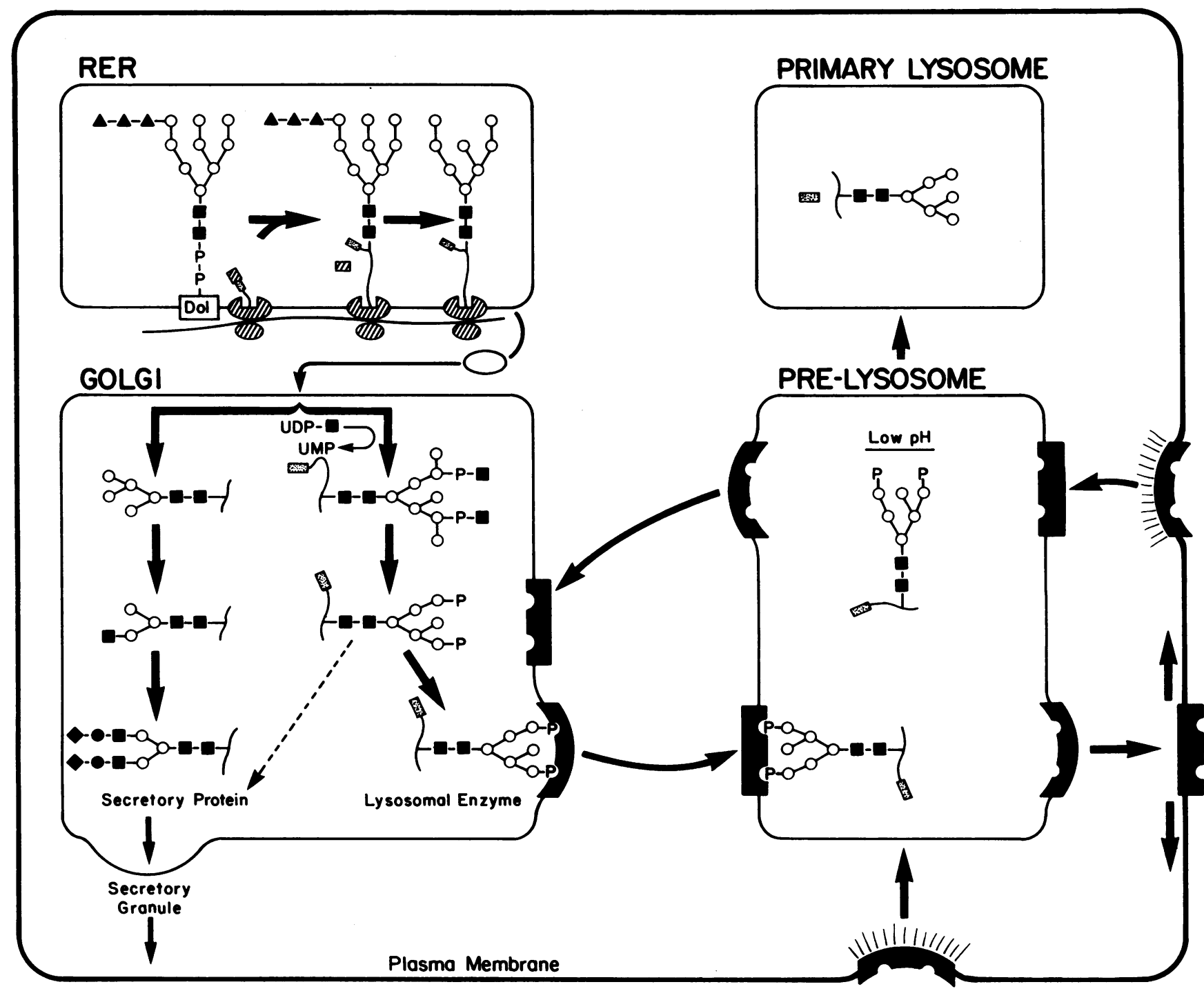

Figure 1. Schematic pathway of lysosomal enzyme targeting to lysosomes. Nascent lysosomal enzymes and secretory proteins are glycosylated in the rough endoplasmic reticulum (RER) by the transfer of a preformed oligosaccharide from dolichol-P-P-oligosaccharide. In the RER, the signal peptides $(\boldsymbol{m})$ are excised. The proteins are translocated to the Golgi where the oligosaccharides of secretory proteins are processed to complex-type units and the oligosaccharides of lysosomal enzymes are phosphorylated. Most of the lysosomal enzymes bind to M6-P receptors ( ) and are translocated to an acidified prelysoso-

mon amino acid sequence. When the amino acid sequences of more lysosomal enzymes are determined with the cloning of these proteins (13-20), homologies may become evident.

Following the generation of the phosphomannosyl residues, the lysosomal enzymes bind to M-6-P receptors in the Golgi. In this way the lysosomal enzymes which remain intracellular are segregated from the proteins that are destined for secretion. The ligand-receptor complex then exits the Golgi via a coated vesicle and is delivered to a prelysosomal staging area where dissociation of the ligand occurs by acidification of the compartment (21). The receptor then recycles back to the Golgi to pick up another ligand molecule, and the lysosomal enzymes are packaged into vesicles to form primary lysosomes. A small amount of the ly- mal compartment where the ligand dissociates. The receptor recycles back to the Golgi and the enzymes are packaged into primary lysosomes where their propieces are cleaved (口s). A small portion of the lysosomal enzymes fail to bind to the receptors and are secreted along with secretory proteins $(-\rightarrow)$. These enzymes may bind to surface

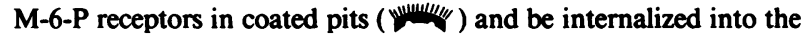
prelysosomal compartment. $\mathrm{n}, \mathrm{N}$-acetylglucosamine; O, mannose; $\Delta$, glucose; $\bullet$, galactose; $\bullet$, sialic acid.

sosomal enzymes, usually $5-20 \%$, is secreted before its delivery to lysosomes. A portion of these enzymes may bind to M-6-P receptors present on the cell surface and be internalized and delivered to lysosomes (22). In fibroblasts, this secretion-recapture mechanism functions as a salvage pathway, which accounts for the delivery of 5-10\% of total lysosomal enzymes to lysosomes (23). A M-6-P receptor has been purified from a variety of tissues and appears to be a single glycoprotein with an apparent molecular weight of 215,000 (24-25), although there is one report indicating that the receptor may consist of smaller subunits (26). This receptor binds acid hydrolases independent of divalent cations. The receptor has been detected in the Golgi complex, coated vesicles, endosomes, and the plasma membrane (27). These var- 
ious pools of the receptor appear to be in rapid equilibrium, since exogenously added antireceptor antibodies quickly interact with all of the intracellular receptor $(90 \%$ of the total) $(27,28)$.

Two groups have used immunocytochemistry to define the precise site in the Golgi where lysosomal enzymes bind to the receptor, and the results have been conflicting. Brown and Farquhar (29), using an immunoperoxidase technique at the electron microscope level, found that immunoreactive receptors were restricted in their distribution to one or two cisternae on the cis side (entry face) of the Golgi stacks of several secretory and absorptive cell types. Receptor was not detected in the trans Golgi (exit face) or in GERL, a special compartment located on the trans aspect of the Golgi complex $(30,31)$. Based on these findings, Brown and Farquhar proposed that lysosomal enzymes bind to the M-6-P receptor in the cis Golgi and are delivered from this site to endosomes and lysosomes via coated vesicles. For this to occur, lysosomal enzymes must be phosphorylated in the cis Golgi. This probably is the case since the two enzymes involved in the generation of the phosphomannosyl residues (phosphotransferase and $\alpha-N$-acetylglucosaminidase) appear to be localized in this region of the Golgi stack (31a). Geuze et al. (32), using an immunoelectron microscopy technique involving ultra-thin cryosections and colloidal gold-protein A conjugates to detect the anti-M-6-P receptor antibodies, found the M-6-P receptor to be distributed throughout the Golgi cisternae (both cis and trans elements) and in the trans-most Golgi elements which correspond to GERL. By performing double-label immunoelectron microscopy using colloidal gold particles of two sizes, it was shown that the lysosomal enzyme cathepsin D colocalized with the M-6-P receptor in all of the Golgi cisternae. On this basis, Geuze et al. proposed that M-6-P receptor/cathepsin D complexes traverse the entire Golgi complex on their way to lysosomes. The basis for these discrepant results is not clear.

Another unresolved problem concerns the mechanism whereby the Golgi-derived vesicles containing the M-6-P receptors with their bound ligand find their way to the proper endosomal compartment. While it is presumed that the receptor must contain sorting sequences which direct this process, they have not been identified. A similar question concerns the mechanism by which the receptor makes it way back to the Golgi after discharging its ligand. The answers to these fascinating questions will almost certainly require the cloning of the receptor and the application of recombinant DNA techniques to study the function of the various portions of this large protein. Several groups are currently trying to clone this receptor and hopefully this will be accomplished in the near future.

During the course of studying the distribution of the 215kD M-6-P receptor among cell types, it was noted that endothelial cells and a number of murine tissue culture lines are deficient in this recpetor (33-35). In spite of totally lacking or having barely detectable levels of receptor, the cells contained high levels of intracellular lysosomal enzymes which were localized to dense granules that are characteristic of lysosomes. Recently, we found that these cells contain a M-6-P receptor which differs from the previously described $215-\mathrm{kD}$ receptor in that it has a requirement for divalent cations (36). Based on this difference, we suggested that the new receptor be termed the cation-dependent M-6-P receptor (M-6-P receptor ${ }^{\mathrm{CD}}$ ) and the original receptor be called the cation-independent $\mathrm{M}-6-\mathrm{P}$ receptor (M-6-P receptor $\left.{ }^{\mathrm{Cl}}\right)$. This new receptor has been purified to homogeneity from detergentsolubilized membranes by chromatography on a lysosomal en- zyme affinity column (37). It is a glycoprotein with a subunit molecular size of $46 \mathrm{kD}$ and appears to be an oligomer composed of three subunits. The M-6-P receptor ${ }^{\mathrm{CD}}$ binds ligands tightly at neutral $\mathrm{pH}$ and releases them at $\mathrm{pH} 5$ or lower. This property is shared by the M-6-P receptor ${ }^{\mathrm{Cl}}$ and by other receptors which deliver and discharge ligands in acidified compartments, e.g., endosomes and lysosomes. The M-6-P receptor ${ }^{\mathrm{CD}}$ is widely distributed among cell types, and consequently, most cells contain both M-6-P receptors. This raises a number of interesting questions concerning the sorting of lysosomal enzymes. Do newly synthesized lysosomal enzymes bind randomly to the different receptors, or do they bind selectively to one or the other receptor? If there is selectivity in receptor binding, what is the structural basis for this? Do the different receptors target acid hydrolases to different classes of lysosomes which may be involved in specialized cellular functions? The detection of a second M-6-P receptor may serve to uncover previously unsuspected complexities of the lysosomal system.

While the M-6-P recognition pathway is clearly important in lysosomal enzyme targeting, there must be mechanisms for localizing acid hydrolases to lysosomes independent of this recognition marker. The evidence for this comes from studies of patients with I cell disease (mucolipidosis II [ML-II]) and pseudoHurler polydystrophy (mucolipidosis III [ML-III]). The cells of these patients are characterized by a deficiency of phosphotransferase activity, which results in an inability to synthesize the phosphomannosyl recognition marker (38-42). As a consequence, newly synthesized lysosomal enzymes are unable to bind to the M-6-P receptors. In some cell types from these patients, such as fibroblasts, the enzymes are secreted into the extracellular milieu rather than targeted to lysosomes. However, in other cells, such as hepatocytes, Kupffer cells, and leukocytes, there are nearly normal levels of lysosomal enzymes even though these cells are also deficient in phosphotransferase activity $(43,44)$. These cells, therefore, must be using a targeting mechanism distinct from the M-6-P pathway. While it seems likely that this targeting is receptor-mediated, attempts to demonstrate a receptor that binds lysosomal enzymes independent of M-6-P have been unsuccessful thus far.

In addition to oligosaccharide processing, lysosomal enzymes undergo further proteolytic processing; thus, all lysosomal enzymes studied to date are synthesized as preproenzymes with amino terminal extensions (45). The prepiece, which is the signal sequence, is cleaved immediately in the endoplasmic reticulum, while the propiece is cleaved later, usually over the course of several hours but occasionally this process requires several days. In some instances there are further internal cleavages of the peptide as well as carboxyl terminal processing (46). This proteolytic processing appears to be initiated in the prelysosomal compartments and is completed after the enzymes arrive in the lysosomes (47). The biologic meaning of this processing is poorly understood. In the case of cathepsin $\mathrm{D}$, the pro sequence probably functions as an activation peptide, perhaps serving to keep the protease inactive until it is sorted from the secretory and membrane proteins. However, other lysosomal enzymes do not appear to be synthesized as inactive zymogens. In these instances, the propieces may have a role in the initial folding of the protein and then may be dispensable as is the $\mathrm{C}$ peptide of insulin. Alternatively, cleavage of the propiece could have a positive role, possibly serving to stabilize the lysosomal enzymes when they reach the acid environment of the endosome and lysosome. An intriguing possibility is that the propiece contains sorting infor- 
mation, perhaps providing the signal for lysosomal enzyme targeting by the M-6-P-independent pathway. This would be similar to the amino terminal sequences which direct the import of proteins into mitochondria and the nucleus. Since mature lysosomal enzymes without propieces can be phosphorylated in vitro by phosphotransferase, the information for this specific interaction cannot be contained in the propiece. The availability of cloned lysosomal enzymes should allow experiments designed to elucidate the role of this proteolytic processing.

While lysosomal storage disorders are usually classified on the basis of the particular enzyme deficiency or the material that accumulates, these diseases can also be grouped according to the site of the block in the life cycle of the lysosomal enzyme. One such classification, as suggested by von Figura et al. (48), is shown in Table I. Examples of each of these classes have been well documented. In three of the groups (III-V), catalytically active enzymes are synthesized but fail to become segregated into lysosomes, are unstable and rapidly inactivated, or lack function due to the absence of activator proteins. Patients with the same enzyme deficiency may have allelic mutations leading to the same defect via different mechanisms. In fact, this is known to be the case in Tay-Sachs disease (53), metachromatic leukodystrophy (62), and Pompe's disease $(56,59)$. It should be noted that this classification is based on our current knowledge of the disease mechanisms, and this list is likely to expand as the pathophysiology of more patients is analyzed at the molecular level.

In view of the complex series of events required for the proper sorting of lysosomal enzymes, it is not surprising that lysosomal storage disorders are being detected where the defect is in the targeting of the lysosomal enzyme rather than in the synthesis of a catalytically active protein. What is unexpected, perhaps, is that defects in targeting are turning out to be relatively frequent. For instance, in a study of acid $\alpha$-glucosidase synthesis in cultured skin fibroblasts from seven unrelated individuals with glycogenosis type II (Pompe's disease), Reuser et al. (55) found that three lines produced normal quantities of the $110-\mathrm{kD}$ precursor form of the enzyme, but conversion to the mature $76-\mathrm{kD}$ enzyme

Table I. General Classification of Lysosomal Storage Disorders*

References

I. Disorders in which no immunologically detectable enzyme is synthesized. This includes conditions with grossly abnormal structural genes.

$49-52$

II. Disorders in which a catalytically inactive polypeptide is synthesized. The mutation may also affect the stability or transport of the polypeptide.

III. Disorders in which a catalytically active enzyme is synthesized that is not segregated into lysosomes.

IV. Disorders in which a catalytically active enzyme is synthesized that is unstable in prelysosomal or lysosomal compartments.

V. Disorders in which activator proteins of lipiddegrading hydrolases are missing.

VI. Disorders in which lysosomal enzyme deficiencies result from intoxication with inhibitors of lysosomal enzyme.

* This classification is based on that of von Figura et al. (48). was either completely absent or extremely inefficient. In all instances glycosylation of the mutant precursors was normal, but mannose phosphorylation could not be detected in two cases. This suggests that either the glycosylated precursor could not be transported from the endoplasmic reticulum to the Golgi, where phosphorylation occurs, or that the mutation resulted in the loss of recognition by phosphotransferase. A similar block has been described in a rare form of Tay-Sachs disease (52). The fibroblasts of this patient synthesize the $\alpha$-chain precursor of $\beta$-hexosaminidase, which is glycosylated but not phosphorylated. The subunit is very insoluble, indicating that the mutation may prevent the transport of the precursor out of the endoplasmic reticulum. Defects in precursor processing have also been described in $\mathrm{G}_{\mathrm{M1}^{-}}$ gangliosidosis (57) and in Gaucher's disease $(67,68)$.

It has already been noted that patients with I cell disease (ML-II) and pseudo-Hurler polydystrophy (ML-III) have a deficiency of phosphotransferase activity. Fibroblasts from patients with ML-II have extremely low or undetectable enzyme levels, whereas fibroblasts from patients with ML-III have some residual phosphorylating activity consistent with their milder clinical course (38-42). Cell fusion experiments have defined complementation groups among various ML-II and ML-III fibroblast lines $(69,70)$. The ML III lines have been placed into two distinct complementation groups, with the possible existence of a third (69). While the fibroblasts of all three groups are deficient in the phosphorylation of lysosomal enzymes, the group IIIC fibroblasts have normal or nearly normal levels of activity toward the simple sugar $\alpha$-methylmannoside, a recognition-independent substrate, whereas the group IIIA (and IIIB) fibroblasts have low levels of activity toward that substrate. Recently, the actual kinetics of phosphorylation of lysosomal enzymes and $\alpha$-methylmannoside by fibroblast extracts of ML-III patients have been analyzed (71). In five instances there was decreased activity toward lysosomal enzymes and $\alpha$-methylmannoside, with the apparent $K_{\mathrm{m}}$ values for all the substrates being normal. Therefore, the residual phosphotransferase in these patients must have an intact recognition function. Presumably, the low enzyme activity is due to decreased synthesis of the enzyme, instability of the enzyme, or synthesis of an enzyme with a defective catalytic function. Fibroblast extracts of three patients (all from complementation group IIIC) displayed normal or nearly normal kinetic parameters when $\alpha$ methylmannoside was the acceptor in the phosphotransferase assays, suggesting the presence of a normal level of the enzyme. However, the affinity of the phosphotransferase for lysosomal enzymes was significantly decreased. Therefore, these patients appear to contain normal levels of phosphotransferase which is defective in its recognition function. These kinetic data establish two distinct types of defects in ML-III patients and provide biochemical evidence consistent with the existence of two complementation groups. Since complementation in somatic cells occurs at the protein level, the demonstration of two complementation groups suggests that the phosphotransferase is an oligomeric protein. While it is not possible to distinguish between an oligomer of identical subunits or one with different specialized subunits, these data are consistent with the proposal that phosphotransferase is a protein which contains a recognition site (or subunit) and a catalytic site (or subunit) that interact to specifically recognize and phosphorylate lysosomal enzymes. The proof of this model awaits the purification of this enzyme. However, this has proven to be difficult due to the trace amounts of enzyme present in tissues.

An interesting Lebanese family has been described in which 
five healthy members have highly elevated plasma lysosomal enzymes (72). Fibroblasts from one of the individuals displayed increased secretion of multiple lysosomal enzymes. The physicochemical properties of the secreted enzymes were different from those found in I cell disease plasma, which led the authors to suggest that there could be a defect in the phosphodiester $\alpha-N$-acetylglucosaminidase that normally exposes the M-6-P recognition marker or in one of the M-6-P receptors. Assays of these activities in the affected fibroblasts were not done.

In conclusion, the targeting of newly synthesized lysosomal enzymes to lysosomes involves a series of discrete steps, each mediated by a specific signal. Some of these signals are protein in nature while others are carbohydrate. The early steps in targeting are shared with proteins destined for secretory granules or the plasma membrane. A number of patients with lysosomal storage disorders have mutations which result in the malfunction of this targeting pathway.

\section{Acknowledgment}

This work was supported by U. S. Public Health Service grant R01 CA 08759.

\section{References}

1. Erickson, A. H., G. E. Conner, and G. Blobel. 1981. J. Biol. Chem. 256:11224-11231.

2. Erickson, A. H., P. Walter, and G. Blobel. 1983. Biochem. Biophys. Res. Commun. 115:275-280.

3. Rosenfeld, M. G., G. Kreibich, D. Popov, K. Kato, and D. D. Sabatini, 1982. J. Cell Biol. 93:135-143.

4. Kornfeld, R., and S. Kornfeld. 1985. Annu. Rev. Biochem. 54: 631-664.

5. Kaplan, A., D. T. Achord, and W. S. Sly. 1977. Proc. Natl. Acad. Sci. USA. 74:2026-2030. 4281 .

6. Reitman, M. L., and S. Kornfeld. 1981. J. Biol. Chem. 256:4275-

7. Waheed, A., A. Hasilik, and K. von Figura. 1982. J. Biol. Chem. 257:12322-12331.

8. Varki, A., and S. Kornfeld. 1981. J. Biol. Chem. 256:9937-9943.

9. Waheed, A., A. Hasilik, and K. von Figura. 1981. J. Biol. Chem. 256:5717-5721.

10. Reitman, M. L., and S. Kornfeld. 1981. J. Biol. Chem. 256: 11977-11980.

11. Lang, L., M. L. Reitman, J. Tang, R. M. Roberts, and S. Kornfeld. 1984. J. Biol. Chem. 259:14663-14667.

12. Kemp, B. E., R. B. Pearson, and C. House. 1983. Proc. Natl. Acad. Sci. USA. 80:7471-7475.

13. Hieber, V. C. 1982. Biochem. Biophys. Res. Commun. 104:12711278.

14. Catterall, J. F., and S. L. Leary. 1983. Biochemistry. 22:60496053.

15. Konings, A., P. Hupkes, R. Versteeg, G. Grosveld, A. Reuser, and H. Galjaard. 1984. Biochem. Biophys. Res. Commun. 119:252-258.

16. Ginns, E. I., P. V. Choudary, B. M. Martin, S. Winfield, J. M. Stubblefield, D. Merkle-Lehman, G. J. Murray, L. A. Bowers, and J. A. Barranger. 1984. Biochem. Biophys. Res. Commun. 123:574-580.

17. Fukushima, H., J. R. De Wet, and J. S. O'Brien, 1985. Proc. Natl. Acad. Sci. USA. 82:1262-1265.

18. O'Dowd, B. F., F. Quan, H. F. Willard, A. M. Lamhonwah, R. G. Korneluk, J. A. Lowden, R. A. Gravel, and D. J. Mahuran. 1985. Proc. Natl. Acad. Sci. USA. 82:1184-1188.

19. Myerowitz, R., and R. Proia. 1984. Proc. Natl. Acad. Sci. USA. 81:5394-5398.

20. Faust, P., S. Kornfeld, and J. M. Chirgwin. 1985. Proc. Natl. Acad. Sci. USA. 82:4910-4914.
21. Gonzalez-Noriega, A., J. H. Grubb, V. Talkad, and W. S. Sly. 1980. J. Cell Biol. 85:839-852.

22. Willingham, M. C., I. H. Pastan, G. G. Sahagian, G. W. Jourdian, and E. F. Neufeld. 1981. Proc. Natl. Acad. Sci. USA. 78:6967-6971.

23. Vladutiu, G. D., and M. Rattazzi. 1979. J. Clin. Invest. 63:595601.

24. Sahagian, G. G., J. Distler, and G. W. Jourdian. 1981. Proc. Natl. Acad. Sci. USA. 78:4289-4293.

25. Steiner, A. W., and L. H. Rome. 1982. Arch. Biochem. Biophys. 214:681-687.

26. Mitchell, D. C., T. Maler, and G. W. Jourdian. 1984. J. Cell Biochem. 24:319-330.

27. Sahagian, G. G. 1984. Biol. Cell. 51:207-214.

28. Gartung, C., T. Braulke, A. Hasilik, and K. von Figura. 1985. EMBO (Eur. Mol. Biol. Organ.) J. 4:1725-1730.

29. Brown, W. J., and M. G. Farquhar. 1984. Cell. 36:295-307.

30. Novikoff, P. M., A. B. Novikoff, N. Quintana, and J. J. Hauw. 1971. J. Cell Biol. 50:859-886.

31. Goldfischer, S. 1982. J. Histochem. Cytochem. 30:717-733.

31a. Goldberg, D. E., and S. Kornfeld. 1983. J. Biol. Chem. 258: 3159-3165.

32. Geuze, H. J., J. W. Slot, G. J. A. M. Strous, A. Hasilik, and K. von Figura. 1984. J. Cell Biol. 98:2047-2054.

33. Hasilik, A., B. Voss, and K. von Figura. 1981. Exp. Cell Res. 133:23-30.

34. Gabel, C. A., D. E. Goldberg, and S. Kornfeld. 1983. Proc. Natl. Acad. Sci. USA. 80:775-779.

35. Robbins, A. R., and R. Myerowitz. 1981. J. Biol. Chem. 256; 10623-10627.

36. Hoflack, B., and S. Kornfeld. 1985. Proc. Natl. Acad. Sci. USA. 82:4428-4432.

37. Hoflack, B., and S. Kornfeld. 1985. J. Biol. Chem. 260:1200812014.

38. Reitman, M. L., A. Varki, and S. Kornfeld. 1981. J. Clin. Invest. 67:1574-1579.

39. Hasilik, A., A. Waheed, and K. von Figura. 1981. Biochem. Biophys. Res. Commun. 98:761-767.

40. Varki, A., M. L. Reitman, and S. Kornfeld. 1981. Proc. Natl. Acad. Sci. USA. 78:7773-7777.

41. Waheed, A., A. Hasilik, M. Cantz, and K. von Figura. 1982. Hoppe-Seyler's Z. Physiol. Chem. 363:169-178.

42. Varki, A., M. Reitman, A. Vannier, S. Kornfeld, J. H. Grubb, and W. S. Sly. 1982. Am. J. Hum. Genet. 34:717-729.

43. Owada, M., and E. F. Neufeld. 1982. Biochem. Biophys. Res. Commun. 105:814-820.

44. Waheed, A., R. Pohlman, A. Hasilik, K. von Figura, A. van Elsen, and J. G. Leroy. 1982. Biochem. Biophys. Res. Commun. 105: 1052-1058.

45. Hasilik, A., and K. von Figura. 1984. In Lysosomes in Biology and Pathology. J. T. Doyle, R. T. Dean, and W. Sly, editors. Elsevier Science Publishers, New York. 3-16.

46. Erickson, A. H., G. E. Conner, and G. Blobel. 1984. In Molecular Basis of Lysosomal Storage Disorders. J. A. Barranger and R. O. Brady, editors. Academic Press, New York. 235-249.

47. Gieselmann, V., R. Pohlmann, A. Hasilik, and K. von Figura. 1983. J. Cell Biol. 97:1-5.

48. von Figura, K., A. Hasilik, and F. Steckel. 1984. In Molecular Basis of Lysosomal Storage Disorders. J. A. Barranger and R. O. Brady, editors. Academic Press, New York. 133-146.

49. Hasilik, A., and E. J. Neufeld. 1980. J. Biol. Chem. 255:49374945.

50. Myerowitz, R., and E. F. Neufeld. 1981. J. Biol. Chem. 256: 3044-3048.

51. Waheed, A., A. Hasilik, and K. von Figura. 1982. Hoppe-Seyler's Z. Physiol. Chem. 363:425-430.

52. von Figura, K., A. Hasilik, F. Steckel, and J. Van de Kemp. 1983. Am. J. Hum. Genet. 36:93-100. 
53. Proia, R. L., and E. F. Neufeld. 1982. Proc. Natl. Acad. Sci. USA. 79:6360-6364.

54. Bach, G., and E. F. Neufeld. 1983. Biochem. Biophys. Res. Commun. 112:198-205.

55. Steckel, F., A. Hasilik, and K. von Figura. 1983. J. Biol. Chem. 258:14322-14326.

56. Reuser, A. J. J., M. Kroos, R. P. J. Oude Elferink, and J. M. Tager. 1985. J. Biol. Chem. 260:8336-8341.

57. Hoogeveen, A. T., H. Graham-Kawashima, A. d'Azzo, and H. Galjaard. 1984. J. Biol. Chem. 259:1974-1977.

58. Hickman, S., and E. F. Neufeld. 1972. Biochem. Biophys. Res. Commun. 49:992-999.

59. Steckel, F., V. Gieselmann, A. Waheed, A. Hasilik, K. von Figura, R. O. Elferink, R. Kalsbeek, and J. Tager. 1982. FEBS (Fed. Eur. Biochem. Soc.) Lett. 150:69-76.

60. Waheed, A., A. Hasilik, and K. von Figura. 1982. Eur. J. Biochem. 123:317-321.

61. D’Azzo, A., A. Hoogeveen, A. J. J. Reuser, D. Robinson, and H. Galjaard. 1982. Proc. Natl. Acad. Sci. USA. 79:4535-4539.

62. von Figura, K., F. Steckel, and A. Hasilik. 1983. Proc. Natl. Acad. Sci. USA.80:6066-6070.

63. Conzelmann, E., and K. Sandhoff. 1978. Proc. Natl. Acad. Sci. USA. 75:3979-3983.
64. Stevens, R. L., A. L. Fluharty, H. Kihara, M. M. Kaback, L. J. Shapiro, B. Marsh, K. Sandhoff, and G. Fischer. 1981. Am. J. Hum. Genet. 33:900-906.

65. Inui, K., M. Emmett, and D. A. Wenger. 1983. Proc. Natl. Acad. Sci. USA. 80:3074-3077.

66. Sandhoff, K. 1984. In Molecular Basis of Lysosomal Storage Disorders. J. A. Barranger and R. O. Brady, editors. Academic Press, New York. 19-49.

67. Dorling, P. R., C. R. Huxtable, and S. M. Colegate. 1980. Biochem. J. 191:649-651.

68. Barranger, J., G. J. Murray, and E. I. Ginss. 1984. In Molecular Basis of Lysosomal Storage Disorders. J. A. Barranger and R. O. Brady, editors. Academic Press, New York. 311-323.

69. Honey, N. K., O. T. Mueller, L. E. Little, A. L. Miller, and T. B. Shows. 1982. Proc. Natl. Acad. Sci. USA. 79:7420-7424.

70. Mueller, O. T., N. K. Honey, L. E. Little, A. L. Miller, and T. B. Shows. 1983. J. Clin. Invest. 72:1016-1023.

71. Lang, L., T. Takahashi, J. Tang, and S. Kornfeld. 1985. J. Clin. Invest. 76:2191-2195.

72. Alexander, D., G. Dudin, F. Talj, F. Bitar, M. Deeb, A. Khudr, M. Abboud, and V. M. Der Kaloustian. 1984. Am. J. Hum. Genet. 36 : 1001-1014. 